\title{
Role of Technology in Sustainable Gambling: Policy Effects of Electronic Card System and Limit Setting
}

\author{
Junhwi Park (i), ${ }^{1}$ SeongRak Choi, ${ }^{2}$ Dohyeong Kim $\left(\mathbb{D},{ }^{3}\right.$ Denise Boots $\mathbb{D}^{3},{ }^{3}$ \\ and Chang Kil Lee $\mathbb{C}^{4}$ \\ ${ }^{1}$ Crime Prevention and Treatment Research Division, Korean Institute of Criminology and Justice, Seoul 6764, Republic of Korea \\ ${ }^{2}$ Department of Business Management, Dongyang Mirae University, Seoul 8221, Republic of Korea \\ ${ }^{3}$ School of Economic, Policy and Policy Sciences, University of Texas at Dallas, Richardson, \\ TX 75080, USA \\ ${ }^{4}$ Department of Urban Policy and Administration, Incheon National University, Incheon 220212, Republic of Korea
}

Correspondence should be addressed to Chang Kil Lee; leechangkil@yahoo.com

Received 21 June 2021; Revised 15 July 2021; Accepted 3 August 2021; Published 12 August 2021

Academic Editor: Ali Ahmadian

Copyright (๑) 2021 Junhwi Park et al. This is an open access article distributed under the Creative Commons Attribution License, which permits unrestricted use, distribution, and reproduction in any medium, provided the original work is properly cited.

\begin{abstract}
With the rapid expansion of the gambling industry in Asian markets over the past decade, South Korea has implemented policies seeking to expand entertainment gambling while simultaneously seeking to reduce possible harms from problem gambling. In 2016, the mandatory electronic players' card (EPC) system was adopted into specific Korean horse and cycling venues to discourage problem gambling behaviors since it prohibits large bets, while permitting other venues to autonomously operate EPC systems. This study compares preliminary data from mandatory versus autonomous venues to explore how EPC systems impact gambling behaviors, revenues, and policies. Overall, electronic cards were more widely adopted in mandatory venues for horse betting and in autonomous venues for cycling betting. Analyses indicate that larger bets were placed at both horse- and cycle-betting venues with autonomous card registration versus mandatory venues. While the EPC system mitigated problem gambling behaviors in horse betting, this impact was not observed for cycle betting. Such differences indicate that users across different types of sport betting exhibit somewhat distinct characteristics and behaviors in using electronic cards, which could shed light on the sustainable gambling strategy of adopting technology-driven EPC systems in sport betting not only in South Korea but also elsewhere around the world.
\end{abstract}

\section{Introduction}

There has been a rapid expansion of the transnational casino industry into Asian markets over the past decade [1]. Asia has become the most dominant regional market shaping the gambling industry, with a compounded expansion rate of roughly 20 percent between 2011 and 2015 and a global market share estimated at roughly $45 \%$ by 2015 [2, 3]. Forecasts regarding the Asian Pacific region continue to point to growth and expansion in the region, with Macau, Australia, and Singapore leading as the top three gambling destinations, respectively [2]. An exception to the explosive Asian growth model comes when looking at South Korea; while an established gambling economy, competition from Macau and Japan has been projected to negatively impact gambling revenues in Korea, leaving this nation with flat or slightly lower revenues when compared to other Asian countries [2]. At the same time, the increasing middle class of Mainland China and change in attitudes toward gambling have resulted in competitive markets rising across Asia to attract tax dollars and revenues, with Korea seeking to attract its share of casino tourism revenues with the adoption of more liberalized legalized gambling policies [4].

Toward this end, and in keeping with worldwide trends expanding gaming in Asian markets, Korea has implemented gradual regulations since the late 2000s by executing a multistep plan by the Korean National Gambling Control Commission (hereinafter the "NGCC"). These initiatives, collectively known as the National Master Plan, represent a public policy response under a responsible gaming framework which seeks to expand entertainment gambling while simultaneously addressing possible harms to individuals, 
families, and communities that come from excessive and irresponsible gambling [5]. At the same time, these policies reflect the Korean government's efforts to positively reshape and shift attitudes toward legalized gambling from one perceived as a "vice" to one that perpetuates the "entertainment" and "fun" of recreational gambling [6]. This dramatic shift in Korean government policies that seek to reframe gambling as a procommunity and recreational activity reflects the more proliberalization Reno Model emulated by other countries such as Singapore, the United States, Australia, and Macau [7, 8].

In 2010, the first stage of the National Master Plan piloted electronic players' card (EPC) systems which was supposed to launch a small number of gambling venues across horse, bicycle, and motorboat racing, casinos, and sports betting sites (e.g., Sports Toto) [9]. Very few individual gamblers actually opted into the card program, and the NGCC reported serious inconveniences for those individuals who tried to use the system. In July of 2012, the NGCC launched a second pilot program after considering feedback from industry stakeholders and experts, with $10 \%$ of all horse- and cycling-racing venues implementing one of two options: (1) venues completely banning cash bets and (2) venues allowing a certain amount of maximum bet. The second National Master Plan began in 2014 with the goal of increasing the ratio of electronic card users and bets made from the cards.

The introduction of the EPC system in Korea was proposed as a policy to address the social negative side effects of the gambling industry [5]. In addition, it was argued that adopting this system would enhance the integrity and transparency of gambling activities as a form of recreation and fun while helping to curb the potential for gambling addictions to form or be furthered at these betting sites [10]. In theory, the introduction of electronic cards discourages problem gambling behaviors because they prohibit an individual from betting over KRW 100,000 in a single game (with an estimated conversion rate of roughly $\$ 1$ $\mathrm{USD}=1100 \mathrm{KRW}$ ). If players are required to bet only by using the electronic card, it is possible to cap a single bet at an amount below KRW 100,000. This adoption of EPC system fundamentally bars any single bet to exceed KRW 100,000 and, hence, it is deemed to improve the efficacy of the regulation on betting amounts and, further, have the benefit of reducing gambling addiction. However, in reality, it is possible to exceed the maximum bet amount by using the EPC for one maximum bet and then placing cash bets for the same race at any venue that allows cash transactions. At casinos, patrons similarly may place two or more bets simultaneously in machines or at tables at the KRW 100,000 maximum amount, thereby bypassing EPC restrictions.

However, significant controversies exist in the empirical literature regarding the impact of the electronic card system on gambling addiction effects and the negative effects derived from the introduction of the electronic card system. If electronic card system is implemented, the revenue would greatly decline, which would harm the business foundation of legal gaming industry and may lead to the decrease in tax revenue [11]. Moreover, the adoption of EPC systems would decrease the privacy of users and further encourage illegal betting due to the maximum caps that players were limited to [12], thereby increasing the side effects such as gambling addiction [13]. Due to such opposing opinions, the NGCC has been continuously delaying the full adoption of the electronic card system in Korea. While relatively more studies have been evaluated on the economic impacts of EPC systems [14] or focused on other types of gambling in Korea, such as casinos [15] and arcade games [16], it appears that there is a lack of support in the literature for the aim of the EPC systems to prevent gambling addiction or enhance customer convenience versus if no EPC system was adopted, for the case of betting on horse and cycle races.

In February of 2016, the Korean government adopted the mandatory use of electronic card into select horse and cycle venues. Hence, while some venues were required to use electronic cards for horse-racing and cycling businesses, others were provided with autonomy-rather than obligation-of choosing to adopt EPC systems. Introducing a mandatory system in specific horsing and bicycling venues while permitting other venues to autonomously operate their businesses with an option of EPC systems in Korea offers researchers an ideal opportunity to explore how EPC systems impact gambling behavior, revenues, and responsible gambling policies. With such selective adoption practices, the Korean government created a natural experiment whereby the policy effects of mandatory adoption of electronic cards can be compared to venues granted the autonomous adoption of electronic cards.

Thus, we aim to evaluate the impacts of the EPC system adopted in specific Korean horse- and bicycling-racing venues on gambling behavior, revenue, and responsible gambling policies. We used the data collected in the project conducted by the authors in 2016 [17] which examined the policy effects of mandatory versus autonomous electronic card systems by comparing measures across horse- and bicycling-racing venues that were required to adopt electronic cards versus other horsing and bicycling venues where adoption of electronic cards was not mandated. The following are the major contributions of this paper:

(i) This paper contributes to the gambling study literature by utilizing government data from the National Gambling Control Commission (NGCC) of Korea as it rolled out an EPC system as both autonomous (voluntary registration) and mandatory (all players must use cards) across select legal horse- and cycle-racing venues

(ii) It is the first study, to our knowledge, to offer an exploratory analysis of empirical data on EPC system from Korea, which highlights the role of technology in sustainable gambling

(iii) It offers a valuable first look into the impact of this launch of selective EPC systems whereby the policy effects of mandatory adoption of electronic cards can be compared to venues granted the autonomous adoption of electronic cards 
The rest of the paper is organized as follows. Section 2 describes the data and methodology of the current study, and Section 3 presents the results on the impact of mandatory and voluntary adoption of EPC systems on gambling outcomes in horse- and cycle-betting venues, respectively. Section 4 discusses the implication of the findings and Section 5 concludes the results of this study.

\section{Materials and Methods}

We aim to make a comparative evaluation on whether there is any difference in gambling behavior and outcomes between mandatory and autonomous policies of operating electronic card system in horse-racing and cycle-racing businesses in South Korea. Mandatory-type venues require the use of electronic cards only when betting at least KRW 50,000 (USD 45 based on a conversion rate of $\$ 1$ $\mathrm{USD}=1110 \mathrm{KRW}$ ), while autonomous-type venues permit bets to be placed in cash or through electronic cards in all bet amount ranges. The key variables to be compared between mandatory-type versus autonomous-type venues include the following: (1) average purchase amount per ticket issued, (2) average purchase amount per person, (3) total number of tickets issued per person, and (4) the proportion of tickets in each betting range among the total number of tickets issued.

The data were collected from nine gambling venues (six horse-racing and three cycle-racing) for 20 weeks between February and June 2016. During this period, NGCC designated three horse-racing venues (Incheon, Jung-Gu; Daegu; and Changwon) and one cycle-racing venue (Gunpo) as mandatory and three horse-racing venues (Incheon, Nam-Gu; Seoul; and Busan) and two cycle-racing venues (Cheonan and Uijeongbu) as autonomous. All venues were comparable in terms of total revenue, total number of customers, and tickets issued. More details of the data can be found in the final project report submitted to National Gambling Control Commission by the authors (2016).

\section{Results}

3.1. Horse Betting. Table 1 summarizes the results of the comparison between mandatory-type venues and autonomous-type venues for horse-betting data in terms of the proportion of cash versus electronic cards among the total number of tickets issued and the total revenue, the average purchase amount per ticket issued and per person, and the proportion of each betting range among the total number of tickets issued.

As shown in Table 1, for both mandatory and autonomous types, cash purchases contributed over $86 \%$ of the tickets issued and revenue, but electronic card usage seemed slightly more active in mandatory-type venues than in autonomous-type venues (13.2\% versus $10.6 \%$ for the number of tickets and $11.3 \%$ versus $9.5 \%$ for total revenue), with marginal significance $(p<0.1)$. Average betting amount per ticket and per person by cash was statistically significantly higher in autonomous-type venues than in mandatory-type venues (KRW 14,307 versus KRW 12,597 for per ticket betting; KRW 546,038 versus KRW 479,493 for per person betting), but average amount of betting per person by electronic card was statistically indifferent between the two types of venues. The gap in per ticket average betting between cash and electronic card purchases was larger in mandatory-type venues (KRW 1,731 for mandatory versus KRW 1,172 for autonomous), while autonomous-type venues had a larger gap in per person average betting between cash and electronic card purchases (KRW 418,209 for mandatory versus KRW 489,150 for autonomous). In addition, there was no statistical difference in the average number of tickets issued per person between autonomous-type and mandatory-type venues, purchased by either cash or electronic card. Interestingly, only less than $2 \%$ of the tickets purchased via electronic cards were priced over KRW 50,000 in mandatory-type venues even if there was no betting limit, while almost 3\% of the tickets purchased using electronic cards were priced over KRW 50,000 in autonomous-type venues. Of course, cash betting over that amount, which was only allowed in autonomous-type venues, took about $5 \%$ among all tickets purchased by cash.

Overall, as for horse betting, it seems apparent that electronic cards were relatively more used in mandatorytype venues where users betted less not only by electronic cards but also by cash. It is also found that high-price betting over KRW 50,000 occurred more frequently in autonomoustype tenders, particularly when purchased by cash. Despite the fact that the average numbers of tickets issued for each customer were similar in both mandatory-type venues and autonomous-type venues, customers tended to spend more in autonomous-type venues where cash betting was entirely flexible.

3.2. Cycle Betting. Likewise, Table 2 summarizes the results of the comparison between mandatory-type venues and autonomous-type venues for cycle-betting data in terms of the proportion of cash versus electronic cards among the total number of tickets issued and the total revenue, the average purchase amount per ticket issued and per person, and the proportion of each betting range among the total number of tickets issued.

Unlike the horse-betting case, for cycle betting, electronic card usage was significantly more active in autonomous-type venues than in mandatory-type venues $(26.3 \%$ versus $12.6 \%$ for the number of tickets and $12.1 \%$ versus $8.4 \%$ for total revenue; $p<0.01$ ), although cash purchases were dominant as well (73-92\%). Similar to the horsebetting case, the average betting amount per ticket and per person by cash was statistically significantly higher in autonomous-type venues than in mandatory-type venues (KRW 30,436 versus KRW 21,594 for per ticket betting; KRW 372,065 versus KRW 278,532 for per person betting), but the opposite was true for the average per ticket betting amount by electronic card (KRW 13,653 for mandatory versus KRW 11,675 for autonomous). Thus, the gap in per ticket or per person average betting between cash and 
TABLE 1: Comparison between mandatory-type and autonomous-type venues in horse betting.

\begin{tabular}{|c|c|c|c|c|c|c|}
\hline \multirow{2}{*}{\multicolumn{2}{|c|}{ Category }} & & \multicolumn{2}{|c|}{ Types } & \multicolumn{2}{|c|}{ Analysis of difference } \\
\hline & & & Mandatory & Autonomous & $t$-value & $\begin{array}{c}\text { Significance } \\
\text { level }\end{array}$ \\
\hline \multirow{2}{*}{\multicolumn{2}{|c|}{$\%$ of cash/cards among total number of tickets issued }} & Cash & 86.85 & 89.40 & 1.508 & \multirow[b]{2}{*}{0.070} \\
\hline & & $\begin{array}{l}\text { Electronic } \\
\text { cards }\end{array}$ & 13.15 & 10.60 & -1.508 & \\
\hline \multirow{2}{*}{\multicolumn{2}{|c|}{$\%$ of cash/cards among total revenue }} & Cash & 88.66 & 90.54 & 1.663 & \multirow[b]{2}{*}{0.053} \\
\hline & & $\begin{array}{l}\text { Electronic } \\
\text { cards }\end{array}$ & 11.34 & 9.46 & -1.663 & \\
\hline \multirow{2}{*}{\multicolumn{2}{|c|}{ Avg. betting per ticket issued (KRW) }} & Cash & 12,597 & 14,307 & 11.550 & 0.000 \\
\hline & & $\begin{array}{l}\text { Electronic } \\
\text { cards }\end{array}$ & 10,866 & 13,135 & 6.138 & 0.000 \\
\hline \multirow{2}{*}{\multicolumn{2}{|c|}{ Avg. betting per person (KRW) }} & Cash & 479,493 & 546,038 & 7.050 & 0.000 \\
\hline & & $\begin{array}{l}\text { Electronic } \\
\text { cards }\end{array}$ & 61,284 & 56,888 & -0.697 & 0.245 \\
\hline \multirow{2}{*}{\multicolumn{2}{|c|}{ Avg. number of tickets issued per person }} & Cash & 38.08 & 38.19 & 0.150 & 0.441 \\
\hline & & $\begin{array}{l}\text { Electronic } \\
\text { cards }\end{array}$ & 5.79 & 4.55 & -1.616 & 0.057 \\
\hline \multirow{8}{*}{$\begin{array}{l}\% \text { of each betting range among total number of } \\
\text { tickets issued }\end{array}$} & \multirow{4}{*}{ Cash } & $\leq \mathrm{KRW} 30,000$ & 90.26 & 90.16 & -0.492 & 0.313 \\
\hline & & $\begin{array}{l}>\text { KRW } 30,000 \\
\leq \text { KRW 50,000 }\end{array}$ & 9.74 & 4.70 & -27.014 & 0.000 \\
\hline & & $\begin{array}{l}>\text { KRW } 50,000 \\
\leq \text { KRW } 70,000\end{array}$ & 0.00 & 1.26 & 97.404 & 0.000 \\
\hline & & $>$ KRW 70,000 & 0.00 & 3.88 & 56.254 & 0.000 \\
\hline & \multirow{4}{*}{$\begin{array}{l}\text { Electronic } \\
\text { cards }\end{array}$} & $\leq \mathrm{KRW} 30,000$ & 94.82 & 92.80 & -5.404 & 0.000 \\
\hline & & $\begin{array}{l}>\text { KRW } 30,000 \\
\leq \text { KRW 50,000 }\end{array}$ & 3.47 & 4.42 & 4.222 & 0.000 \\
\hline & & $\begin{array}{l}>\text { KRW } 50,000 \\
\leq \text { KRW 70,000 }\end{array}$ & 0.76 & 1.27 & 8.825 & 0.000 \\
\hline & & $>$ KRW 70,000 & 0.95 & 1.51 & 5.233 & 0.000 \\
\hline
\end{tabular}

electronic card purchases was much larger in autonomoustype venues: KRW 18,761 (autonomous) versus KRW 7,941 (mandatory) for per ticket average betting and KRW 320,466 (autonomous) versus 253,044 (mandatory) for per person average betting. The average number of tickets issued per person was statistically different between autonomous-type and mandatory-type venues for both cash and electronic card purchases. Contrary to the horse-betting case, $4.28 \%$ of the tickets purchased via electronic cards were priced over KRW 50,000 in mandatory-type venues, while $2.67 \%$ of the tickets purchased using electronic cards were priced over KRW 50,000 in autonomous-type venues. Cash betting over that amount, which was only allowed in autonomous-type venues, took almost $20 \%$ among all tickets purchased by cash, which is a lot larger compared to only $5 \%$ in the horsebetting case.

The most noticeable difference for cycle betting in comparison to horse betting is that EPCs were more frequently used in autonomous-type venues, although highprice betting over KRW 50,000 was still prevalent among cash purchases. In addition, compared to autonomous-type venues, a larger number of tickets were issued per person on average when paid by cash, but fewer tickets were issued among card purchases in mandatory-type venues. However, it seems also true for cycle betting that customers tend to spend more in autonomous-type venues, particularly by cash, since no limit was placed on cash betting.
3.3. Weekly Patterns of EPC Usage and Average Betting Amount. Figure 1 shows the weekly trends of EPC usage rate for 20 weeks comparing autonomous-type and mandatory-type venues since the introduction of a mandatory system in specific horsing and bicycling venues in 2016. Interestingly, the EPC usage rate is higher in mandatorytype venues for horse betting, while it is substantially higher in autonomous-type venues for cycle betting throughout the period. Except for the last few weeks, about $10-15 \%$ of tickets in mandatory-type venues for both horse and cycle betting were issued as EPC throughout the period, but a substantial difference was found for EPC use in autonomous-type venues between horse betting (5-10\%) and cycle betting (20-30\%). Such difference implies that EPC adoption is highly dependent upon how each gambling industry promotes the use of EPC, such as marketing, promotion, and advertisement, particularly for autonomous-type venues. It is also noticeable that, in horse-betting sites, the EPC use in autonomous-type venues was lower initially but continuously caught up with that in mandatory-type venues. Both autonomous-type and mandatory-type venues for horserace betting induced a massive addition of EPC users after the 17th week, due to industry-wide campaigns.

Figure 2 shows whether or not each horse betting gambler's betting pattern has changed over time during the 20-week period in autonomous-type and mandatory-type venues. It appears that the change in their betting 
TABLE 2: Comparison between mandatory-type and autonomous-type venues in cycle betting.

\begin{tabular}{|c|c|c|c|c|c|c|}
\hline \multirow{2}{*}{\multicolumn{2}{|c|}{ Category }} & & \multicolumn{2}{|c|}{ Types } & \multicolumn{2}{|c|}{ Analysis of difference } \\
\hline & & & Mandatory & Autonomous & $t$-value & $\begin{array}{l}\text { Significance } \\
\text { level }\end{array}$ \\
\hline \multirow{2}{*}{\multicolumn{2}{|c|}{$\%$ of cash/cards among total number of tickets issued }} & Cash & 87.39 & 73.74 & -13.191 & 0.000 \\
\hline & & $\begin{array}{l}\text { Electronic } \\
\text { cards }\end{array}$ & 12.61 & 26.26 & 13.191 & 0.000 \\
\hline \multirow[b]{2}{*}{$\%$ of cash/cards among total revenue } & & Cash & 91.65 & 87.88 & -5.879 & 0.000 \\
\hline & & $\begin{array}{l}\text { Electronic } \\
\text { cards }\end{array}$ & 8.35 & 12.12 & 5.879 & 0.000 \\
\hline \multirow[b]{2}{*}{ Avg. betting per ticket issued (KRW) } & & Cash & 21,594 & 30,436 & 32.021 & 0.000 \\
\hline & & $\begin{array}{l}\text { Electronic } \\
\text { cards }\end{array}$ & 13,653 & 11,675 & -5.143 & 0.000 \\
\hline \multirow[b]{2}{*}{ Avg. betting per person (KRW) } & & Cash & 278,532 & 372,065 & 10.898 & 0.000 \\
\hline & & $\begin{array}{l}\text { Electronic } \\
\text { cards }\end{array}$ & 25,488 & 51,599 & 8.769 & 0.000 \\
\hline \multirow{2}{*}{\multicolumn{2}{|c|}{ Avg. number of tickets issued per person }} & Cash & 12.89 & 12.23 & -2.140 & 0.019 \\
\hline & & $\begin{array}{l}\text { Electronic } \\
\text { cards }\end{array}$ & 1.86 & 4.41 & 10.796 & 0.000 \\
\hline \multirow{8}{*}{$\begin{array}{l}\% \text { of each betting range among total number of } \\
\text { tickets issued }\end{array}$} & \multirow{4}{*}{ Cash } & $\leq \mathrm{KRW} 30,000$ & 72.92 & 68.04 & -6.916 & 0.000 \\
\hline & & $\begin{array}{l}>\text { KRW } 30,000 \\
\leq \text { KRW } 50,000\end{array}$ & 27.08 & 12.27 & -23.220 & 0.000 \\
\hline & & $\begin{array}{l}>\text { KRW } 50,000 \\
\leq \text { KRW } 70,000\end{array}$ & 0.00 & 3.41 & 59.064 & 0.000 \\
\hline & & $>$ KRW 70,000 & 0.00 & 16.28 & 64.451 & 0.000 \\
\hline & \multirow{4}{*}{$\begin{array}{l}\text { Electronic } \\
\text { cards }\end{array}$} & $\leq \mathrm{KRW} 30,000$ & 90.83 & 91.89 & 1.954 & 0.029 \\
\hline & & $\begin{array}{l}>\text { KRW } 30,000 \\
\leq \text { KRW } 50,000\end{array}$ & 4.89 & 5.44 & 1.570 & 0.063 \\
\hline & & $\begin{array}{l}>\text { KRW } 50,000 \\
\leq \text { KRW 70,000 }\end{array}$ & 1.05 & 0.92 & -2.302 & 0.014 \\
\hline & & $>$ KRW 70,000 & 3.23 & 1.75 & -4.489 & 0.000 \\
\hline
\end{tabular}

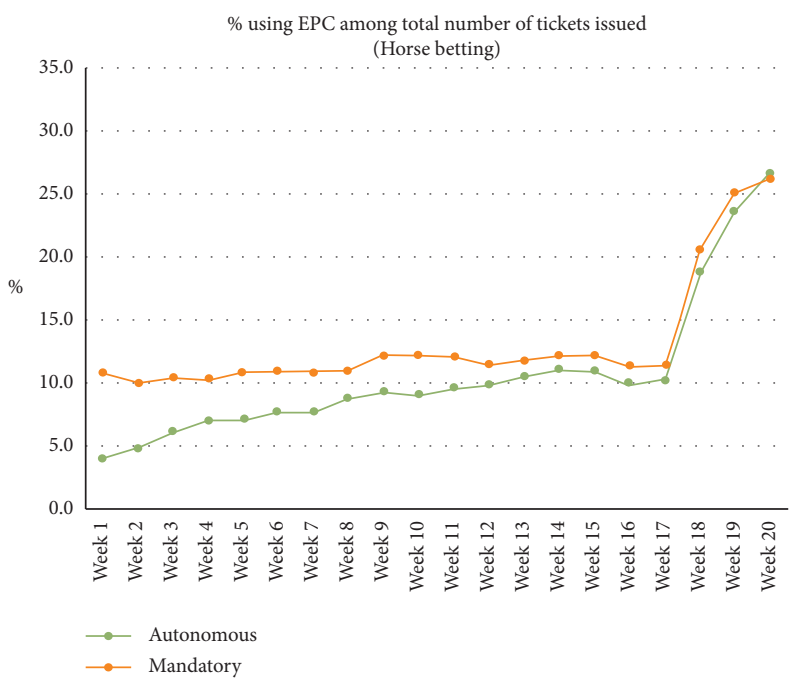

(a)

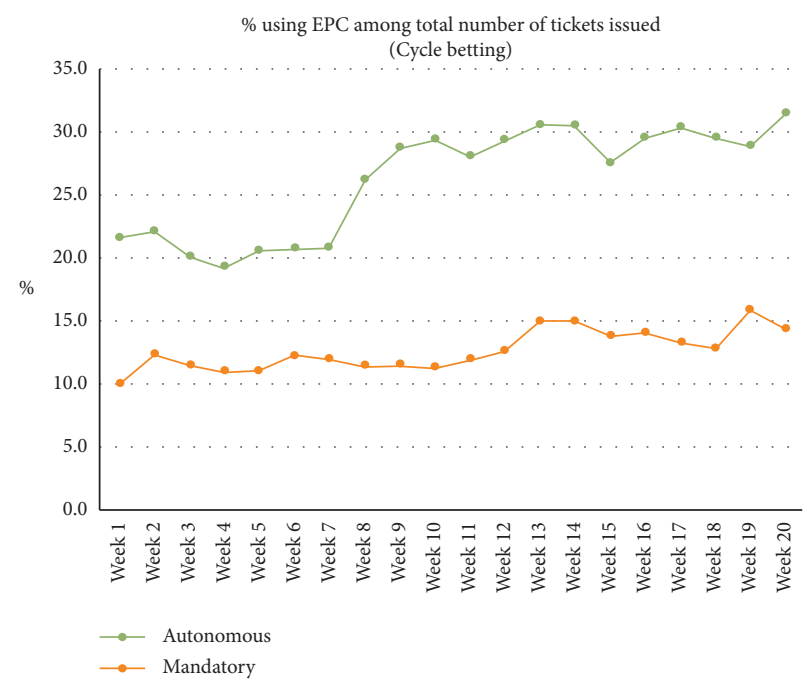

(b)

FIGURE 1: Weekly trends of EPC usage rate (autonomous-type versus mandatory-type venues): (a) horse betting; (b) cycle betting.

preferences (cash versus EPC betting) was minimal during the first few months, except that the betting amount by EPC systems continued to increase in autonomous-type venues. However, the cash betting amount significantly dropped after around the 17 th week, mostly due to the dramatic increase of the betting amount by EPC. Considering that cash purchases consist of $85-90 \%$ of the total tickets issued in both types of venues, a significant reduction effect of the average betting amount per person began to be conspicuous after 3-4 months of implementing the EPC system, in both 


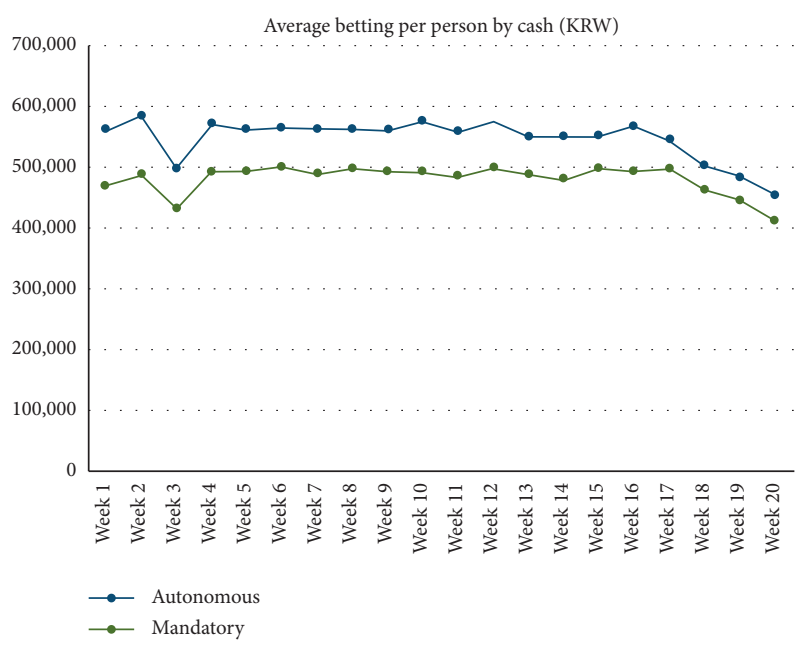

(a)

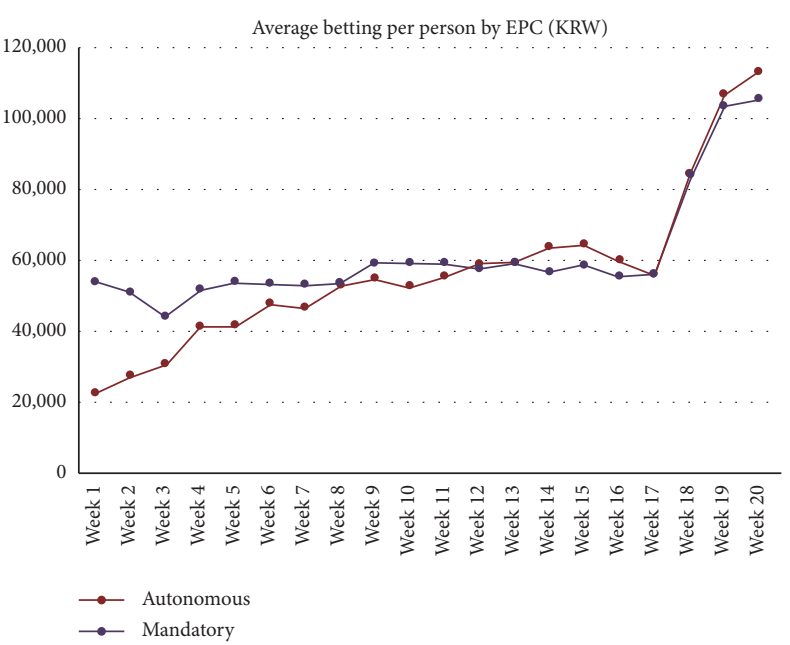

(b)

FIGURE 2: Weekly trends of average betting amount per person in horse betting (cash versus EPC; autonomous-type versus mandatory-type venues): (a) cash betting; (b) EPC betting.

autonomous-type and mandatory-type venues. The findings imply that the potential role of EPC in mitigating problematic gambling behaviors could be marginal in the beginning but could be eventually sizable even in autonomous settings, if the EPC system is constantly and effectively promoted and marketed. However, these temporal patterns were not observed for the cycle-betting data, which may indicate some unique difference in gambling behaviors or EPC operations in the horse- and cycle-betting industry in South Korea.

\section{Discussion}

This study evaluated the impacts of the electronic players' card (EPC) system adopted in specific Korean horse- and bicycling-racing venues on gambling behavior, revenue, and responsible gambling (RG) policies by comparing the venues with the mandatory versus autonomous adoption of electronic cards. To our knowledge, the present article is the first to examine preliminary data available from the NGCC which include various outcomes of EPC systems in Korea. While RG principles would suggest that EPC systems might discourage problem gambling behaviors regardless of venue type, the findings from this study reveal significant differences between the two types of sports betting. As expected, we found that electronic cards were more widely adopted not only in mandatory-type venues for horse betting but also quite unexpectedly in autonomous-type venues for cycle betting. Such conflicting results might imply that the adoption rate of EPC systems depends on the level of marketing or promotion efforts across the venues rather than the types of EPC systems (mandatory versus autonomous) or sport betting game (horse versus cycle betting).

For both horse betting and cycle betting, it is found that that larger bets were more frequently placed at venues with autonomous card registration compared to mandatory-type venues, mostly due to high-priced cash purchases. The average number of tickets and betting amount per person using EPCs were higher in mandatory-type venues for horse betting than in autonomous-type venues for cycle betting. During the 20-week study period, the EPC use in autonomous venues was lower initially but gradually caught up with that in mandatory-type venues for horse betting, while the EPC use was always higher in autonomous-type venues for cycle betting. Similar to other literatures which suggest that bet limits can have a positive influence on problem gambling behaviors (see Auer et al., 2020), the current results suggest that the continuing operation of EPC system in horse betting may have some positive influence on alleviating problem gambling even on a voluntary basis in autonomous settings. Yet this impact was not observed for cycle betting. Such differences indicate that users across these different types of sports betting exhibit distinct characteristics or gambling behavior in using electronic cards.

There are intriguing policy considerations for the NGCC and the gambling industry in Korea to consider with the implementation of EPC systems across various gambling venue types. For example, some research has shown that, in some countries such as Australia, "overall, it appears that playing with an account card or ticket assists players to gamble more responsibly compared to players using cash" ([18], p. 232). This study may also inform public health professionals and policymakers regarding the potential role of EPC in mitigating negative gambling behaviors, which may contribute to positive policies that reduce the social and economic costs of problem gambling addiction in Korea. Korea's National Master Plan is an ambitious one that is being presented as a blueprint for responsible gaming policies [5]. Yet, this plan has been slower to be adopted than originally designed by the NGCC and has received a significant amount of critique from the Korean gambling industry regarding mandatory enrolment and implementation [9]; this opposition is similar to that derision seen in other areas of the world where cashless payment technologies have been adopted and more industry responsibility has been endorsed (see Nisbett, Jackson, and Christensen, 2016). 
Despite the contribution of this study to the literature, several limitations should be noted. First of all, while the study findings show anecdotal evidence to explain differences between the two types of sports betting and the two types of EPC operation (mandatory versus autonomous) observed here, these data do not allow for more advanced statistical testing and modelling. Ideally, more data will be collected, which will allow for control and statistical significance to be tested in regression models. Second, the reduction effect of average betting amounts on EPC use may not be directly related to a decline in problem gambling behavior; this finding could be only a temporary adjustment phenomenon. Lastly, an additional limitation is the small sample size of the data from a total of nine gambling venues collected over 20 weeks, which clearly limits the statistical inferences that can be drawn and the overall generalizability. Accessing additional data from Korea, which allows for more statistically advanced analyses across longer data periods, is a natural next step to determine if the results reported here are consistent beyond the preliminary snapshots currently available. Although future studies should focus on overcoming the present study's limitations, the unique contribution of the current article is that it allows an initial look at the impact of implementing mandatory EPC operations on sites with a naturally occurring experimental design. As such, the results of this pilot study can be used as a foundation for more nuanced discussions regarding the expansions of designing and operating the EPC system as well as the long-term implications of such policies.

\section{Conclusions}

As Asia continues to dominate the largest gambling market in the world [2], liberal-leaning gambling jurisdictions simultaneously struggle with rebranding the gambling enterprise in the public eye from one of a banned, sinful activity to one that embraces the community and accepts gambling as a harmless, fun entertainment. The incentives to legitimize gambling are considerable, as revenues from tourism and gambling are economically significant. As Korea appears to be adopting a more expansive policy for gambling similar to Macau and Australian Reno/liberal risk model [1], common social perceptions regarding mainstream acceptance, the founding and integration of community-based gambling facilities, and deeply ingrained cultural issues regarding gambling fallacies within Korean and Asian culture are some of the critical topics that must be addressed to ensure responsible gaming practices. Per "responsive regulation" ideals perpetuated in more liberalized/ individual risk localities, the mandatory versus autonomous adoption of EPC systems could be viewed as a collaborative relationship between government regulators and the gambling industry in cooperation with community stakeholders [8]. On the other hand, the adoption of more public health focused approaches, such as requiring players to enrol and register cards with betting limits, could also be viewed as an effort toward reducing gambling-related harm, which is more consistent with the public health consumer protectionoriented regulatory scheme $[1,19,20]$.
Public health perspectives that inform policy and practice present opportunities for increased consideration and evaluation of the overall well-being of populations impacted by prevention, promotion, and protections that minimize harm [21]. It also emphasizes that responsible gambling could focus on the individual as well as the community with a more holistic view [22]. Toward that end, recent public health focused research suggests that gambling harm is not limited to problem gamblers with clinical levels of addiction but that at-risk gamblers account for a substantial and major proportion of all negative gambling outcomes incurred [23]. Moreover, some scholars argue that a shift toward self-regulation of the gambling industry forces to a public health consumer protection model is ideal for responsible gambling, since it embraces the operator duties to limit harms, endorsing practices such as mandatory precommitment limits and fees imposed on locals who gamble [24]. Without question, such conceptual issues point to the importance of further studying Korea's natural experiments with EPC systems and considering how these mandatory versus voluntary adoptions of EPC systems impact policies, practices, and procedures. It remains to be seen as to what the dominant model will become in Korea. Such considerations are central to reducing harms and ensuring consumer protection while balancing the interests of industry and government ventures.

Questions remain regarding whether the findings of this study would hold up across time, with larger sample sizes, or across gambling venues. Further qualitative inquiries that delve into the thoughts and feelings of Korean gamblers as they adopted EPCs that limit bets would be helpful in better understanding decision-making and the impact of RG tools to support healthy gambling habits. Future studies might seek a mixed-methods approach that would allow for such analyses. While empirical literature has suggested that bet limits (voluntary and mandatory) have beneficial results as part of RG strategies to control problem gambling behaviors in other parts of the world (e.g., Auer and Griffiths, 2021), the data in the present study do not allow for a comprehensive analysis. Are there cultural differences in attitudes toward RG tools and implementation across varying gambling venues? These issues are the ones to pursue in future research as well.

\section{Data Availability}

The data that support the findings of this study are available from the first author (krpark@kic.re.kr) upon reasonable request.

\section{Conflicts of Interest}

The authors declare that there are no conflicts of interest.

\section{Acknowledgments}

This work was supported by Incheon National University Research Grant in 2018. 


\section{References}

[1] L. Hancock and Z. Hao, "Gambling regulatory regimes and the framing of "responsible gambling" by transnational casino corporations: Asia-pacific regimes in comparative perspective," Asia Pacific Journal of Public Administration, vol. 38, no. 3, pp. 139-153, 2016.

[2] Price Waterhouse Cooper, Global Gaming Outlook, Price Waterhouse Cooper, London, UK, 2015, https://www.pwc. $\mathrm{com} / \mathrm{mt} / \mathrm{en} /$ industry-sectors/assets/global-gaming-outlook. pdf.

[3] South Australian Centre for Economic Studies, Responsible Gambling and Casinos: Report for Gambling Research Australia, University of Adelaide, Adelaide, Australia, 2016.

[4] N. Gambits, "News in brief about the gaming world," Gaming Law Review and Economics, vol. 19, no. 9, pp. 631-633, 2015.

[5] National Gambling Control Commission. National Gambling Control Commission: Introduction. 2020 https://www.ngcc. go.kr/eng/committee/introduction.do.

[6] K. Jayasuriya, "Regulatory regionalism in the Asia-pacific: drivers, instruments and actors," Australian Journal of International Affairs, vol. 63, no. 3, pp. 335-347, 2009.

[7] K. Chambers, Gambling for Profit: Lotteries, Gaming Machines and Casinos in Cross-National Focus, University of Toronto Press, Toronto, Canada, 2011.

[8] L. Hancock, Regulatory Failure: The Case of Crown Casino, Australian Scholarly Publishing, Melbourne, Australia, 2011.

[9] National Gambling Control Commission. National Master Plan for Responsible Gambling. 2020 https://www.ngcc.go.kr/ eng/police/plan.do.

[10] National Gambling Control Commission. Policy \& System. $2020 \mathrm{https} / / /$ www.ngcc.go.kr/eng/police/policy.do.

[11] B. J. Bernhard, A. F. Lucas, and D. S. Jang, Responsible Gaming Device Research Report, International Gaming Institute, University of Nevada, Las Vegas, NV, USA, 2006.

[12] Kyunghee University Industry-Academia Cooperation Foundation, Research on the Legitimacy of Electronic Card Introduction in Gangwon Land, Gangwon Land Policy Report, Kyunghee University Industry-Academia Cooperation Foundation, Seoul, Republic of Korea, 2009.

[13] National Strategy Institute, Research on the Possibility of Adopting Electronic Card System in Lottery Business, Korea Ministry of Finance and Planning, Sejong-Si, Republic of Korea, 2013.

[14] J. Jeong, "Economic value of green card for restricting issuance of cycling and boat racing tickets," The Korean Society of Sports Science, vol. 21, no. 6, pp. 677-687, 2012.

[15] H. Seo, "Exploratory research on the effects of introduction of electronic cards on casinos for residents," Travel and Leisure Research, vol. 22, no. 6, pp. 579-593, 2010.

[16] J. Park, D. Kim, and M. Heo, "Research on electronic card system in arcade games from the perspective of relaxing gaming nature," Journal of Korea Game Society, vol. 11, no. 6, pp. 181-191, 2011.

[17] J. Park, A Pilot Evalation Study on Electronic Card System in Gambling Industry, National Gambling Control Commission, Seoul, Korea, 2016.

[18] S. Nisbet, A. Jackson, and D. R. Christensen, "The influence of pre-commitment and associated player-card technologies on decision making: design, research and implementation issues," International Journal of Mental Health and Addiction, vol. 14, no. 3, pp. 228-240, 2016.
[19] J. Wright and B. Head, "Reconsidering regulation and governance theory: a learning approach," Law \& Policy, vol. 31, pp. 193-216, 2009.

[20] N. Hing, A. M. T. Russell, and A. Hronis, "What behaviours and cognitions support responsible consumption of gambling? Results from an expert survey," International Journal of Mental Health and Addiction, vol. 15, no. 6, pp. 1320-1341, 2017.

[21] D. A. Korn and H. J. Shaffer, "Gambling and the health of the public: adopting a public health perspective," Journal of Gambling Studies, vol. 15, no. 4, pp. 289-365, 1999.

[22] C. S. Campbell and G. J. Smith, "Gambling in Canada-from vice to disease to responsibility: a negotiated history," $\mathrm{Ca}$ nadian Bulletin of Medical History, vol. 20, no. 1, pp. 121-149, 2003.

[23] M. Browne, Assessing Gambling-Related Harm in Victoria: A Public Health Perspective, Victorian Responsible Gambling Foundation, Melbourne, Australia, 2016.

[24] L. Hancock and G. Smith, "Critiquing the Reno model I-iv international influence on regulators and governments (20042015)-the distorted reality of "responsible gambling"” International Journal of Mental Health and Addiction, vol. 15, no. 6, pp. 1151-1176, 2017. 